University of Wollongong

Research Online

Faculty of Engineering and Information

Faculty of Engineering and Information

Sciences - Papers: Part A

Sciences

$1-1-2015$

\title{
A new mixing technique for solidifier and dredged fill in coastal area
}

Wenhui Shi

Shanghai Maritime University

Qingsheng Chen

National University of Singapore, qingshen@uow.edu.au

Sanjay Nimbalkar

University of Wollongong, sanjayn@uow.edu.au

Wenbai Liu

Shanghai Maritime University

Follow this and additional works at: https://ro.uow.edu.au/eispapers

Part of the Engineering Commons, and the Science and Technology Studies Commons

Research Online is the open access institutional repository for the University of Wollongong. For further information contact the UOW Library: research-pubs@uow.edu.au 


\title{
A new mixing technique for solidifier and dredged fill in coastal area
}

\begin{abstract}
One of the major drawbacks of the conventional method of land reclamation, which involves mixing cement with the dredged soils at the disposal site, is the high cost associated with the manufacturing and transportation. In this study, a new solidified dredged fill (SDF) technique and a new additive is proposed and their applications into practice are discussed. Unlike the conventional approach, the dredged marine soils were mixed with the solidifiers using a new designed mixing technique prior to its transport to site, which could significantly reduce the cost of site machinery and effectively reclaim land with adequate engineering properties necessary for the construction of infrastructure. To evaluate the performance of the reclaimed land using the proposed technique, a series of laboratory and field tests (viz. static and dynamic cone penetration tests, plate load tests) were conducted on the ground filled with and without solidified dredged marine soils, respectively. The results show that the engineering behaviour of the reclaimed land with dredged marine soils using SDF technique can be significantly improved. The SDF technique combined with the newly designed mixing system improved the performance of ground and is thus proved to be both cost-effective and safe.
\end{abstract}

\section{Disciplines}

Engineering I Science and Technology Studies

\section{Publication Details}

Shi, W., Chen, Q., Nimbalkar, S. \& Liu, W. (2017). A new mixing technique for solidifier and dredged fill in coastal area. Marine Georesources and Geotechnology, 35 (1), 52-61. 


\title{
A New Mixing Technique for Solidifier and Dredged Fill in Coastal Area
}

\author{
Wenhui Shi ${ }^{\mathrm{a}}$, Qingsheng Chen ${ }^{\mathrm{b}}$, Sanjay Nimbalkar ${ }^{\mathrm{c}}$ and Wenbai Liu ${ }^{\mathrm{d}}$ \\ a Postgraduate Student, Ocean Science and Engineering College, Shanghai Maritime University, Shanghai City, \\ Shanghai, 201306, China; Email: smilecatxiao@163.com \\ b Research Fellow, Department of Civil and Environmental Engineering, Faculty of Engineering, National \\ University of Singapore, Singapore, 118707. Email: ceecq@nus.edu.sg \\ ${ }^{\mathrm{c}}$ ARC Research Fellow, Faculty of Engineering, University of Wollongong, Wollongong City, NSW 2522, Australia; \\ email: sanjayn@uow.edu.au \\ ${ }^{\mathrm{d}}$ Professor of Ocean Science and Engineering College, Shanghai Maritime University, Shanghai City, Shanghai, \\ 201306, China; Email: liuwb8848@163.com
}

\begin{abstract}
:
One of the major drawbacks of the conventional method of land reclamation, which involves mixing cement with the dredged soils at the disposal site, is the high cost associated with the manufacturing and transportation. In this study, a new solidified dredged fill (SDF) technique and a new additive is proposed and their applications into practice are discussed. Unlike the conventional approach, the dredged marine soils were mixed with the solidifiers using a new designed mixing technique prior to its transport to site, which could significantly reduce the cost of site machinery and effectively reclaim land with adequate engineering properties necessary for the construction of infrastructure. To evaluate the performance of the reclaimed land using the proposed technique, a series of laboratory and field tests (viz. static and dynamic cone penetration tests, plate load tests) were conducted on the ground filled with and without solidified dredged marine soils, respectively. The results show that the engineering behaviour of the reclaimed land with dredged marine soils using SDF technique can be significantly improved. The SDF technique combined with the newly designed mixing system improved the performance of ground and is thus proved to be both cost-effective and safe.
\end{abstract}

Keywords: Dredged marine soil; land reclamation; laboratory tests; field tests, solidified dredged fill 


\section{Introduction}

In order to meet ever growing demand of development and shortage of land, various types of infrastructure (such as industrial complexes, recreational facilities and airports) have been forced to be constructed on reclaimed lands near ports and harbours in many countries, such as Japan, China, Singapore and Australia. As a result, a huge amount of fill is needed to build such facilities on the large scale. For instance, about 180 million $\mathrm{m}^{3}$ of sand was used for the offshore project of the Kansai International Airport in constructing an artificial island of $4.37 \mathrm{~km}$ by 1.23 km plan area (Arai, 1991; Kanda et al., 1991). Approximately 200 million $\mathrm{m}^{3}$ of sand were used for the reclamation of a total land area of about 3000 ha in the Changi East reclamation project in Singapore during the period from 1992 to 2004 (Arulrajah et al. 2009). To avoid the high cost associated with the collection of large-volume fills (e.g., sand fill and hill-cut materials), recycling the dredged mud for construction purposes in coastal areas has been much preferred solution. This not only mitigates the environmental pollution caused by large amount of unwanted dredged mud disposal, but also addresses the shortage of reclamation fill (Porbaha et al. 1999; Tan et al., 2002).

Over the past decades, extensive studies dealing with characterization and stabilization of dredged marine soils have been reported, and dredged material has been recognized as a promising marine resource for the backfills used for land reclamation (e.g., Schroeder and Shileds, 1983; Austin, 1995; Vaghar et al., 1997; Palermo and Wilson, 1997; Naik and Singh, 1997; Liu et al, 2015). Generally, the marine soils were dredged from navigation channels and construction sites of large-scale port and harbor projects, and transferred to the reclamation sites through the pipelines. These recently originated dredged marine soils do not undergo much consolidation. As a result, it has a very limited (or no strength) and high compressibility (Chiu et 
al. 2009). Therefore, effective treatment is imperative to achieve adequate engineering properties suitable for construction. Various treatment methods, such as chemical solidification, or installation of the prefabricated vertical drains (PVD) for accelerating consolidation process, have been often carried out to improve the engineering behaviour of the reclaimed land (Bergado et al 1999; Chu et al, 2006; Arulrajah et al. 2009). However, these methods have many drawbacks. For example, while an application of PVD supplemented by preloading has been often used to accelerate the consolidation rate of soft soil, many field tests revealed that the application of PVDs was not much effective for the soft sensitive marine clays (e.g. Wijeyakulasuriya et al 1999; Ameratunga et al. 2010) and various difficulties arose in the installation of PVDs in the ultra-soft dredged soils (Bo et al., 2005). Moreover, this often takes many years to reach full consolidation of dredged soils owing to its very high water content and low permeability, which significantly delays the commencement of infrastructure construction (Chu et al., 2006). Whereas, the conventional solidification method for mixing the solidifier (e.g. cement) with the dredged marine soils in the reclaimed land can effectively accommodate the need for significant development of strength of the dredged ground in a relatively shorter period. Nerveless, this attracts high cost, as the machinery that must be employed at different stages of manufacturing and transport to the project site is needed (Porbaha et al., 1999). For instance, about $70 \%$ of the project cost was used for the machinery used for restoration of a sea wall in Port Island that was damaged because of the Kobe earthquake, where cement-treated dredged marine soils were used (Kimura, 1996; Ingaki et al, 1996).

With the aims of reducing the cost of reusing dredged marine soils for land reclamation, a solidified dredged fill (SDF) technology was proposed by Sakamoto (1998), which involved mixing the solidifiers (e.g., cement) with dredged marine soils at high water content prior to be 
dumped into the project site. Thus, unlike the conventional solidification method which involves mixing the solidifiers with dredged mud after they are dumped into the project site, SDF technique can significantly eliminate the additional foundation work subsequent to reclamation while allowing handling of large amounts of modified dredged mud, thereby substantially reducing the cost, especially for large scale projects (Porbaha et al., 1999). So far, SDF technique has been successfully applied in several projects in the past, such as the Ishinomaki reclamation project (Sakamoto, 1998) and Central Japan International Airport man-made island project (Kitazume and Satoh, 2003). However, due to the huge cost needed for field tests, there is a serious lack of sufficient data on the field performance of the engineered material, even though various mixes have been designed and tested in the laboratory (e.g. Naik and Singh, 1997; Horpibulsuk et al. 2013; Chen and Indraratna, 2014a, b; Chen et al. 2014).

In this study, a new SDF technique was presented with a new solidifier and a newly designed mixing system, aiming to reduce further the cost of reusing dredged marine soils for land reclamation. To evaluate the application of the proposed SDF technique in the world's largest land reclamation project in Shanghai, a series of laboratory and field tests were carried out for the trial situ construction site. Field tests included dynamic cone penetration tests, in-situ plate load tests and static cone penetration tests, while laboratory tests included direct shear tests and odometer tests. For comparison, a total of 26 field tests were conducted on the ground filled with solidified and non-solidified dredged materials, respectively. A new designed equipment for the novel SDF technique and the construction procedure is proposed, and the relevant test results are presented and discussed.

\section{Project Descriptions}


The site is located in the Hengsha east shoal reclamation project at the Shanghai reach of Yangtze River (Hengsha Island), China (Figure 1). In the project, over $480 \mathrm{~km}^{2}$ of land needs to be reclaimed, thus urgently needing a huge amount of filled materials (Tang et al. 2013). In this area around Shanghai reach of the Yangtze River, the annual production of dredged materials from the deepwater channel dredging projects is up to 100 million $\mathrm{m}^{3}$ (Liu et al. 2015; Zhao and Yang, 2015), which has put a serious threat to ecosystem of the ocean and raised a significant pressure on the navigation channels. A prospective solution to such a matter is to reuse the dredged materials as the reclamation filling materials at a relatively low cost, which will bring a huge amount of benefits in both economical and environmental aspects for the large scale reclamation projects. The objective of the current work is to evaluate the field performance of improved ground by using the proposed SDF technique before its further widespread application for land reclamation projects in Shanghai, and other coastal regions.

The project site is shown in Figure 2a, where the ground is the naturally reclaimed dredged marine soils that were delivered from the ocean and have undergone consolidation about two years. Three zones (i.e. Natural zone; Zone 1 and Zone 2) located nearby the embankment were selected for the field tests. The layout of these study zones and field testing points in the site is shown in Figure 3. Summary of the field tests carried out in this project is listed in Table 1. Zone 1 and Zone 2 are the areas filled with the solidified dredged marine soils using SDF technique with different mixing systems, while the Natural Zone is the ground filled with non-solidified dredged marine soils but which has been consolidated for around two years (Figure 2b). The dredged marine soil is classified as silty soil, and its particle size distribution is shown in Figure 4. The dredged marine soils from Natural Zone has water content of $30.5 \%$, bulk density of 19.3 
$\mathrm{kN} / \mathrm{m}^{3}$, while for the fresh dredged marine soil, the water content is up to $148.6 \%$. The field investigation started from early August, 2014, and ended at late October, 2014.

\section{Laboratory Testing and Field Application}

\subsection{Materials and Laboratory Testing}

To produce the solidifiedd dredged materials, a new lime-cement based addictive mixed with a new activator was used in this study. The major constituent of the activator is lignin, which is a complex phenolic polymer made from the polymerization of aromatic alcohol. Extensive tests have been carried out by the authors and the results showed that, compared to the traditional cement agents, this new agent is more effective for the solidification of unstable soils, especially for the dredged soils with high water content (Liu et al, 2015). Prior to the field tests, the amount of additive powder required to be mixed with the dredged soils needs to be determined. A parameter 'mixing ratio' $(\lambda)$ is defined as the ratio of the weight of dry additive powder to the weight of dredged soils. A series of oedometer tests were performed on the solidified dreaded specimens with varying mixing ratio (i.e., $\lambda=2,4,5,6,8,12$ ) and the corresponding compression modulus of the specimens is shown in Figure 5. It is noted here that, following the recommendations made by Burland (1990), a soil vibrating mixer was used to mechanically mix the dredged soil with the solidifier powder until an uniform sample was attained. The mixed materials with given amount were then placed into a stainless steel cylindrical mold $38 \mathrm{~mm}$ in diameter and $76 \mathrm{~mm}$ in height. The vibration method was used to prevent air entrapment during the preparation process, which was conducted at room temperature. Similar method was used by other researchers (e.g., Liu et al. 2015). All the treated specimens were sealed by plastic wrap and stored in a humidity controlled room at a constant temperature $\left(20 \pm 2^{\circ} \mathrm{C}\right)$ for 28 days. 
The test results show that the compression modulus Es increases gradually at low mixing ratios ( $\lambda \leq 6$ ), while Es increases rapidly when $\lambda$ is beyond 6 . In order to obtain the solidified dredged soil with sufficient flow ability and adequate strength, $\lambda=8$ is adopted in this project using trial and error method. The corresponding compression modulus Es is about $24 \mathrm{MPa}$ which can provide sufficient stiffness necessary for the given ground conditions.

\subsection{Newly Designed Mixing System}

The mixing condition of the dredged marine soils with the solidification agent is one of the key factors governing the engineering behaviour of the solidified dredged geomaterials. Many attempts were made to design the effective mixing system by Sakamoto (1998). It was reported that, when the solidifier was directly injected into the compressed-air transfer pipeline to mix with soft mud, the solidifier gets concentrated at the air-phase parts, and no uniform mixing of materials can be expected. The schematic mixing and transportation system (OS-1) is shown in Figure 6a. Based on various experiments, a new mixing system (i.e., OS-2) was updated, where the expansion pipe with a larger diameter than the transfer pipeline diameter was inserted midway through the pipeline (Figure 6b), and the dredged marine soils with a good mixing condition with solidifier can be obtained (Sakamoto, 1998).

Due to the huge cost of the field testing, no further updated mixing system has been reported in the literature to the best knowledge of the authors. In this study, in order to find a solution to reduce the cost of reusing dredged marine soils as filling materials for land reclamation in the large scale project in Shanghai, an attempt was further made to upgrade the existing mixing system for better mixing conditions of dredged marine soils with solidifier, to achieve better engineering properties. The two newly designed mixing and transportation systems (i.e. NS-1 
and NS-2) for SDF technique, including the size information for each section of the systems are shown in Figure 7, respectively. The main update of the NS-1 system (Figure 7a) is that in NS-1 system, the fresh dredged materials transferred by the main pipeline, and the solidified dredged materials were created in the sub-pipeline before disposal to the project site, which can eliminate long-distance transferring of solidified dredged soils and avoid the solidified dredged materials being blocked in the pipeline. Compared to NS-1 system, as shown in Figure 7b, an updated mixing system was designed in NS-2 system, where a pipeline with internal thread as shown in Figure $7 \mathrm{c}$ was connected to the mixing section with enlarged diameter with the aim of further improving mixing condition of dredged marine soils with solidifier. The length of this pipeline (4 m length used in this study) can be adjusted to achieve the optimum quality of mixing condition.

Due to the installation of internal thread, a strong turbulent flow were expected to be induced for the mixed materials, which could further improve the mixing conditions. The internal thread containing $75 \mathrm{~mm}$ long projections with tapered angle of 60 degree allows the development of separation turbulence induced by rapid expansion in the cross sectional direction as shown in Figure 7c. The adhesive (boundary) resistance developed along these internal threads prolongs the transfer duration providing sufficient time to develop an optimum mix before these materials are transferred over a long distance. The strong turbulent conditions in addition to the boundary resistance avoids the necessity of further diluting the mix with water or other lubricating fluid for better mixing operations. Thus this method can promote the effective use of disposal sites, enabling long-distance transfer of dredged marine soils in bulk amounts, as also highlighted in the present study.

\subsection{Construction Procedure of SDF Technique}


Figure 7 shows a schematic illustration of the proposed process of collecting, transporting and solidification, and placing process of the dredged marine soils for land reclamation. The construction site is shown in Figure 8a and 8b. Following the approach proposed by Sakamoto (1998), the stepwise procedure is described follows:

(i) Dredging and transporting: The marine soils dredged from the seabed or from navigation channels, are stored in a floating tank on a barge. Large objectives, if any, are screened by installing a vibrating sieve.

(ii) Feeding and transporting: the dredged material is injected to the transporting system under pressure in a rigid pipe ( $1 \mathrm{~m}$ in diameter). The pressure applied depends on many factors, including the type and density of dredging, the length of the pipeline and the desired rate of production.

(iii) Mixing additives: Mixing system was designed to produce the solidified dredged marine soils mixed with addictives. As discussed earlier, two newly designed mixing systems (i.e. NS-1 and NS-2) were used (Figure 7a and 7b, respectively). Several attempts were made to investigate the quality of mixing conditions of the dredged soils with solidifier. To obtain an effective mixing condition for the solidified materials in the sub-transporting pipe, a section of pipe with enlarged diameter was used. In the NS-2 system, an additional pipeline with internal thread was connected with the mixing section. The length and diameter of the pipeline for each part are shown in Figure 7a and 7b, respectively, which was found to be optimum.

(iv) Relieving and casting: The solidified dredged materials were then relived and casted into the designed site location under pressure. To ensure that the difference of the engineering properties of the ground between Zone 1 and Zone 2 were mainly caused by the SDF Technique with 
different mixing system, two square pits with a trial depth of $0.6 \mathrm{~m}$ (Figure 8c), were excavated and the bottom of the pits was levelled before the disposal of the solidified dredged marine soils.

\subsection{In-situ Application: Field Tests}

Prior to the field tests, samples were collected at the first day and 86 days after the completion of construction for laboratory tests (i.e., direct shear tests) from Zone 1 and Zone 2, respectively. This was done to investigate the effect of curing time on the engineering properties of the improved ground. The field tests including dynamic cone penetration tests, plate load tests and static cone penetration tests were then carried out at Zone 1, Zone 2 and the Natural Zone, respectively.

\section{Results and Discussions}

\subsection{Direct Shear Tests}

A series of direct shear tests were conducted on the specimens obtained from the improved ground filled with solidified dredged marine soils at both Zone 1 and Zone 2, when curing time was 1 and 86 days, respectively. The values of shear strength parameters (cohesion $c$ and friction angle $\phi$ ) are shown in Table 2. It is observed that the shear strength of specimen increased significantly with the increase of curing time. For the specimens from Zone 1, it is observed that the cohesion $c$ and friction angle $\phi$ were $0.64 \mathrm{kPa}$ and $17.33^{0}$ when curing time was 1 day only, while $c$ and $\phi$ was increased to $9.5 \mathrm{kPa}$ and $26^{\circ}$, respectively, when curing time was 86 days. In contrast, the cohesion $c$ and friction angle $\phi$ of the specimens obtained from Zone 2 were 1.23

$\mathrm{kPa}$ and $19.2^{0}$, respectively, when curing time was 1 day only, which were increased to be 14.0 $\mathrm{kPa}$ and $28.6^{0}$ after the curing time was 86 days. This implies that, the dredged soils underwent a 
significant improvement in shear strength due to the treatment via SDF technology and the updated system, respectively (i.e. Figures 7a, 7b). The laboratory results thus confirmed the effectiveness of the SDF technique in dealing with the dredged soils for land reclamation. On the other hand, it was found that the shear strength of specimens recovered from Zone 2 was significantly higher than those from Zone 1 . This could be attributed to a better mixing condition of the dredged soils with the solidifier obtained using the updated system (i.e. Figure 7b and 7c).

\subsection{Dynamic cone penetration test}

Dynamic cone penetration testing is a useful quick method of determining the relative stiffness and density of the superficial deposits. In this study, twelve dynamic cone penetration tests were conducted on the ground filled with solidified (1 8) and non-solidified dredged materials (9 12), respectively. The dynamic cone penetration test apparatus was equipped with a conventional

probe head with a $40 \mathrm{~mm}$ diameter cone-shape tip of $60^{\circ}$ apex angle. A hammer with mass of 10 kg was dropped from the standard height of $500 \mathrm{~mm}$ and blow count was recorded at every 300 $\mathrm{mm}$ depth until the required depth is attained. The dynamic cone penetration test was terminated when three successive blow counts exceeded 50, or when the probing rod rebounded.

Figure 9 shows the comparison of the dynamic cone penetration test results between the ground filled with solidified dredged soils (i.e., Zone 1 and Zone 2) and the ground filled with nonsolidified dredged soils (i.e. Natural Zone). The results are plotted along the depth. The designed depth of ground for improvement is $0.6 \mathrm{~m}$, and four dynamic cone penetration tests were conducted for each zone. It is seen that, the number of blows $\left(\mathrm{N}_{10}\right)$ increased in the case of the improved ground and this increase was significant within a depth of about less than $1 \mathrm{~m}$. For example, the average number of blows for Zone 1 and Zone 2 within $0.6 \mathrm{~m}$ depth of ground was 
increased to 19 , and 27 , respectively, while the $\mathrm{N}_{10}$ for Natural zone was only 7 . Thus, $\mathrm{N}_{10}$ for Zone 1 and Zone 2 were 2.71 and 3.86 times greater than that for Natural Zone, in spite the fact that the dredged marine soils were reclaimed and consolidated for over two years. Moreover, it is seen that $\mathrm{N}_{10}$ for Zone 1 and Zone 2 beyond the depth of $0.6 \mathrm{~m}$ also increased significantly due to the injection of solidified dredged soils into the deeper layer of the ground during construction process, but this effect was diminished with the increasing depth. This further emphasizes the effectiveness of the SDF technology in dealing with the dredged marine soils for land reclamation. Moreover, when the field results from Zone 1 and Zone 2 were compared, it was evident that the number of blows in Zone 2 was significantly higher than that in Zone 1 . This finding was consistent with the results of direct shear testing which indicated higher shear strength of specimens obtained from Zone 2 in comparison to that from Zone 1. Thus, the SDF technique with undated mixing system (NS-2) gives improved ground conditions representing better engineering properties.

\subsection{Static cone penetration test}

The static cone penetration test is an effective in-situ field test to determine the geotechnical engineering properties of soils and to assess stratification (heterogeneous) of subsurface layers. A total of twelve static cone penetration tests were performed in this study, where eight tests were carried out on the ground filled with solidified dredged soils (1 8), and four tests were conducted on the ground filled with non-solidified the dredged soils (9 12). The static cone penetration test apparatus was equipped with a conventional probe head (cone) with a $43.7 \mathrm{~mm}$ diameter cone-shape tip of $60^{\circ}$ apex angle. According to the GB 50021-2001 (2009 Edition) Code for investigation of geotechnical engineering, the cone on the end of a series of rods was 
pushed into the ground at a constant rate of $0.0015 \mathrm{~m} / \mathrm{s}$, and the measurements were made of the cone resistance $\left(q_{c}\right)$ at the interval of $0.1 \mathrm{~m}$.

Figure 10 presents the comparison of test results for the ground filled with solidified dredged soils (i.e., Zone 1 and Zone 2) and for the ground filled with non-solidified dredged soils (Natural Zone). Similar to dynamic cone penetration, these results are also plotted along the depth. Four static cone penetration tests were conducted on the ground in each zone. Small deviation between the test data of the cone resistance against the depth is observed, which implies achievement of identical ground improvement across the study zones. Figure 10 shows that the cone resistances for the improved ground at Zone 1 and Zone 2 were significantly greater than those at Natural Zone, especially within the depth of $0.6 \mathrm{~m}$. At a depth of about $0.2 \mathrm{~m}$ from the ground surface, significant peaks were observed for Zone 1 and Zone 2. The average values of cone resistance obtained from the ground within $0.6 \mathrm{~m}$ at Zone 1 and Zone 2 are $3.0 \mathrm{MPa}$ and 3.9 MPa, respectively, while the cone resistance for the ground in Natural Zone is only $0.51 \mathrm{MPa}$. In other word, $q_{c}$ for Zone 1 and Zone 2 is 5.88 and 7.65 times greater than that for Natural Zone. This aspect significantly highlights the effectiveness of the SDF technique in dealing with the soft dredged marine soils. Again, on the basis of the comparison of the results obtained from Zone 1 and Zone 2, it was obvious that better engineering behaviour can be achieved adopting the SDF technique with newly designed mixing system.

\subsection{In-situ Plate Load Test}

The plate load test is a reliable in-situ test used for determining the ultimate load bearing capacity and the settlement under a given load, which are one of primary concerns in practice. In this study, two in-situ plate loading tests were conducted on the improved ground filled with 
solidified dredged soils in Zone 1 and Zone 2, respectively. It is noted that, for the ground filled with the non-solidified dredged soils (Natural Zone), no in-situ plate load test was carried out as it was found that the strength of the soft ground was still very low. A $25 \mathrm{~mm}$ thick steel plate with square plate of $300 \mathrm{~mm}$ was used in this project. To ensure proper horizontal alignment, the plate was placed on a coarse sand layer with thickness of $20 \mathrm{~mm}$. Nine sets of loading (namely 111, 167, 222, 278, 333, 389, 444, 500 and $556 \mathrm{kPa}$ ), were designed to applied on the plate. When the settlement was less than $0.1 \mathrm{~mm}$ per hour over a 2 hour period, the next increment was loaded.

Figure 11 shows the in-situ plate loading test results for the ground for Zone 1 and Zone 2, respectively. It can be observed that the settlements of ground in Zone 1 and Zone 2 under the maximum load (556 kPa) were $8.73 \mathrm{~mm}$ and $6.59 \mathrm{~mm}$, respectively. Also, no clear shear failure points can be found from the load-settlement curves for the ground at both Zone 1 and Zone 2, which implies that their ultimate bearing capacities exceed $556 \mathrm{kPa}$. According to the "Code for Design of Building Foundation (GB50007-2011)”, the characteristic value of bearing capacity (allowable bearing capacity) can be determined in term of the allowable settlement (s). In this study, the allowable settlement $s$ was determined by the ratio ' $s / b=0.01$ ', where $b$ is the width of the steel plate used in the plate load tests $(b=300 \mathrm{~mm})$. As a result, the characteristic value of bearing capacity for the ground in Zone 1 and Zone 2 based on the allowable settlement $s$ were determined to be $291 \mathrm{kPa}$ and $349 \mathrm{kPa}$, respectively (Figure 11). The unloading part (elastic rebound) of load-settlement curve depicts favourable implications on the load-bearing capacity. Therefore, it is evident that SDF technique can provide significant improvements in the soft dredged soil, thereby obtaining sufficient bearing capacity for infrastructure development. Moreover, better engineering properties of the ground can be obtained by SDF technique with 
updated mixing system (Figure 7b and 7c) compared to the existing systems. The effectiveness of well dredged fill techniques can be ascertained in terms of mechanical proofs and economic factors. As discussed in preceding sections, mechanical proofs were carried out from direct shear test, dynamic cone penetration test, static cone penetration test, and in-situ plate load test. While Authors acknowledge that these discussions are only focused on the influences of individual factor as combined effects of these factors could not be studied. This is limitation of our study. The economic factors are discussed in the following section.

\section{Economic Considerations}

Cost is one of the major concerns before adopting any method to reuse the dredged marine soils for land reclamation. The cost can be divided into (1) capital cost and (2) operating and maintenance cost. The capital cost consists of direct costs required for equipment operation including equipment rental, installation, instrumentation and control, piping, electrical, and material costs for dealing with soft dredged marine soils for land reclamation. The total capital costs can be derived by obtaining cost estimates for the rented equipment, and then applying a ratio factor to estimate other direct and indirect costs (Wilson, 1993). In this study, ratio factor of 15 is used for preliminary cost estimates. The operating and maintenance costs are considered $4 \%$ of total capital costs. Our analysis indicates that costs associated with traditional technique such as PVDs may cost up to about 40.5 USD per sq. m. On the contrary, it only costs approximately 27.4 USD per sq. m. by using the proposed SDF technology. These costs can be

reduced more when SDF technique was applied to larger scale project and using more effective solidifier. However this could not ascertain within the scope of this study.

\section{Conclusions}


This study presents a new mixing technique for solidifier and dredged marine soils in coastal areas. The effectiveness of this new technique is demonstrated by a series of laboratory and insitu field tests conducted on the ground filled with and without solidified dredged marine soils. The following conclusions can be drawn:

(a) The proposed SDF technique can be both cost-effective eliminating the high cost of machinery that used in the conventional method. It is also technically feasible alternative as the SDF technique combined with a revised mixing system can yield the reclaimed land with better engineering properties. This may be attributed to the improved mixing conditions by the additional pipeline with internal thread installed next to the mixing section.

(b) The engineering properties of reclaimed land can be significantly improved in a relatively shorter term (86 days) in contrast to other existing approaches such as use of PVD to accelerate the consolidation, which is often a time consuming process. After curing time of 86 days, the average value of cone resistance increased to $3.9 \mathrm{MPa}$; and the corresponding allowable bearing capacity increased to $349 \mathrm{kPa}$. Thus, the reclaimed land can be rendered suitable for the construction of infrastructure.

(c) The SDF technique combined with a revised mixing system can yield the reclaimed land with better engineering properties. This may be attributed to the improved mixing conditions by the additional pipeline with internal thread installed next to the mixing section.

(d) The economic analysis indicates that the cost of land reclamation is approximately 27.4 USD per square meters due to application of the newly proposed technique. This cost is significantly lower compared to other ground improvement techniques prevalent in practice. 


\section{Acknowledgments}

The authors appreciate the financial support provided by: National Natural Science Foundation of China (51078228); The Chinese national Marine public welfare industry special funds scientific research projects (201105024-5); The Research Innovation Projects of 2013 Shanghai Postgraduate (20131129); The Top Discipline Projects of the Shanghai Municipal Education Commission, China.

\section{References}

Ameratunga, J., De Bok, C., Boyle, P., and Berthier, D. (2010). Ground improvement in Port of Brisbane (PoB) clay. ISSMGE Bulletin, 4(2), 28-54.

Arai Y. (1991). Construction of an artificial offshore island for the Kansai International Airport, Special lecture. GEOCOST 91, Yokohama, 1-17.

Arulrajah A., Bo M. W., Chu J. and Nikraz H. (2009) Instrumentation at Changi land reclamation project, Singapore. Proceedings of the ICE - Geotechnical Engineering, 162(1): 33-40.

Austin T. (1995). A second life for dredged material. Civil Engineering, 65 (11), 60-63.

Bergado D.T., Ruenkrairergsa T., Taesiri Y. and Balasubramaniam A.S. (1999) Deep soil mixing used to reduce embankment settlement. Proceedings of the ICE - Ground Improvement, 3,145162.

Bo M.W., Choa V., Wong K.S. (2005). Reclamation and soil improvement on ultra-soft soil. Ground Improvement, 9(1), 23-31.

Burland, J.B. (1990). On the compressibility and shear strength of natural clays. Geotechnique 40 (3), 329-378.

Chen Q.S., Gao G.Y., Yang J. (2011). Dynamic response of deep soft soil deposits under multidirectional earthquake loading, Engineering Geology, 121(1), 55-65. 
Chen Q.S., Indraratna B., Carter J., Rujikiatkamjorn C. (2014). A theoretical and experimental study on the behaviour of lignosulfonate-treated sandy silt. Computers and Geotechnics, 61:316-327.

Chen Q.S., Indraratna B. (2014a). Deformation Behavior of Lignosulfonate-Treated Sandy Silt under Cyclic Loading. Journal of Geotechnical and Geoenvironmental Engineering, 10.1061/(ASCE)GT.1943-5606.0001210, 06014015.

Chen Q.S., Indraratna B. (2014b). Shear Behaviour of sandy silt treated with lignosulfonate. Canadian Geotechnical Journal. 10.1139/cgj-2014-0249

Chiu C.F., Zhu W., Zhang C.L.(2009). Yielding and shear behavior of cement-treated dredged materials. Engineering Geology 103 (1-2), 1-12.

Chu J., Bo M.W., and Choa V.(2006) Improvement of ultra-soft soil using prefabricated vertical drains. Geotextiles and Geomembranes, 24(6), 339-348.

GB 50021-2001 (2009 Edition). Code for investigation of geotechnical engineering. China Architecture \& Building Press, Beijing, 2009.

Horpibulsuk, S., Rachan, R., Suddeepong, A., Liu, M. D. \& Du, Y. Jun. (2013). Compressibility of lightweight cemented clays. Engineering Geology, 159 59-66.

Hua Y. (2014) Legal regulation of land reclamation in China' coastal areas, Coastal Management, 42:1, 59-79.

Ingaki H., Iai S., Sugano T., Yamazaki H. and Inatomi T. (1996) Performance of caisson type quay walls at Kobe Port. Soils and Foundations, Special Issue, 119-136.

Kanda K., Suzuki S., and Yamagata N. (1991). Offshore soil investigation at Kansai International Airport. GEOCOST 91, Yokohama, 33-38. 
Kimura M. (1996) Damage statistics of Kobe earthquake. Soil and Foundations, Japanese Geotechnical Society, Special Issue, Jan., 1-5.

Kitazume, M., and Satoh, T. (2003) Development of a pneumatic flow mixing method and its application to Central Japan International Airport construction. Ground Improvement, 7(3):139148.

Liu W.B., Chen Q.S., Chiaro G. and Jiang H.M. (2015). Effect of a cement-lignin agent on the shear behavior of Shanghai dredged marine soils. Marine Georesources \& Geotechnology. DOI: 10.1080/1064119X.2015.1024903.

Morohoshi, K., Yoshinaga, K., Miyata, M., Sasaki. I., Saitoh, H., Tokoro, M., Fukuda, N., Fujii, T., Yamada, K., and Ishikawa, M. (2010). Design and long-term monitoring of Tokyo international airport extension project constructed on super-soft ground. Geotechnical and Geological Engineering, 28(3):223-232.

Naik T. and Singh S.C. (1997). Permeability of flowable slurry materials containing foundry sand and fly ash. Journal of Geotechnical and Geoenvironemtnal Engineering, 123(5): 446-450.

Palermo M.R. and Wilson J.R. (1997) Dredging state of the practice-Crops of Engineers Perspective. Proceedings of Dredging and Management of Dredged Material, Geotechnical Special Publication 65, 1-11.

Porbaha A., Hanzawa H. and Shima M.. (1999) Technology of air-transported stabilized dredged fill. Part 1: Pilot study. Ground Improvement, 3, 49-58.

Sakamoto, A. (1998). Cement and soft mud mixing technique using compressed air-mixture pipeline: Efficient solidification at a disposal site. Terra et Aqua, 73, 11-22.

Schroeder P.R. and Shields F.D. (1983). Chemical clarification of dredged material. Journal of Environmental Engineering, ASCE, 109, 2, 414-427. 
Tan T.S., Goh T.L., and Yong K.Y. (2002). Properties of Singapore marine clays improved by cement mixing. ASTM Geotechnical Testing Journal, 25(4), 422-433.

Tang, C., Ji L., and Jia Y.S. (2013) Study of implement scheme for using Yangtze estuary waterways dredged soil to Hengsha east shoal reclamation. Engineering Science, 6, 91-98.

Vaghar S., Donovan J., Dobosz K., and Clary J. (1997). Treatment and Stabilization of dredged harbor bottom sediments; CA/T Project, Boston. Proceedings of Dredging and Management of Dredged Materials, Geotechnical Special Publication, ASCE, 65, 105-121.

Wijeyakulasuriya, V., Hobbs, G. and Brandon, A. (1999). Some experiences with performance monitoring of embankments on soft clays. Proceedings of 8th ANZ Conference on Geomechanics, Hobart, 783-788.

Wilson, D. J. (1993). Hazardous waste site soil remediation: theory and application of innovative technologies (Vol. 6). CRC Press.

Zhao D.Z., Yang Y.J. (2015) Framework suggestion on the beneficial use of dredged material at the Shanghai reach of Yangtze River, Hydro-Science and Engineering, 1, 82-88. 


\section{Table List}

Table 1 Summary of the field tests in this study

Table 2 Shear strength of the specimen obtained from reclaimed land

\section{Figure List}

Figure 1 Location of the study site for Hengsha reclamation project

Figure 2 Project site reclaimed filled with non-solidified dredged soils (a) Part of reclaimed land for Hengsha east shoal reclamation project; (b) Project site for current study

Figure 3 Layout of In-situ field testing points

Figure 4 Particle size distribution of typical fresh dredged marine soil

Figure 5 Variation of Compression modulus Es with different mixing ratio $\lambda$ for solidified dredged materials

Figure 6 Schematic illustrations of the mixing and transportation systems by Sakamoto (1998)

Figure 7 Schematic illustrations of newly designed mixing and transportation systems

Figure 8 Construction site for land reclamation using solidified dredged fills (a) dumping solidified dredged marine soils into the project site; (b) pumping additive powder into fresh dredged marine soils prior to dumping process (c) Schematic illustration of land reclamation work in this study (Zone 1 and Zone 2)

Figure 9 Comparison of In-situ Dynamic Penetration Test results for the natural reclaimed and the treated land

Figure 10 Comparison of cone penetration test results for ground at the natural reclaimed and the treated land

Figure 11 Comparison of In-situ Plate Loading Test results for the natural reclaimed and the treated land 
Table 1 Summary of the field tests in this study

\begin{tabular}{|c|c|c|c|}
\hline Zone ID & Filling material & Test type & Test ID \\
\hline \multirow[t]{3}{*}{ Zone 1} & $\begin{array}{l}\text { Solidifed dredged soils using } \\
\text { SDF technique with the mixing } \\
\text { system (NS-1) }\end{array}$ & Dynamic penetration test & $1,2,3,4$ \\
\hline & & In-situ plate loading test & I \\
\hline & & Cone penetration test & $1,2,3,4$ \\
\hline \multirow[t]{3}{*}{ Zone 2} & $\begin{array}{l}\text { Solidifed dredged soils using } \\
\text { SDF technique with updated } \\
\text { mixing system (NS-2) }\end{array}$ & Dynamic penetration test & $5,6,7,8$ \\
\hline & & In-situ plate loading test & II \\
\hline & & Cone penetration test & $5,6,7,8$ \\
\hline \multirow{2}{*}{$\begin{array}{l}\text { Natural } \\
\text { Zone }\end{array}$} & Non-solidifed dredged soils & Dynamic penetration test & $9,10,11,12$ \\
\hline & & Cone penetration test & $9,10,11,12$ \\
\hline
\end{tabular}

Table 2 Shear strength of the specimen obtained from reclaimed land

\begin{tabular}{cccc}
\hline Zone details & Curing time (days) & $\mathrm{c}(\mathrm{kPa})$ & $\phi\left(^{0}\right)$ \\
\hline Zone 1 & 1 & 0.64 & 17.33 \\
& 86 & 9.5 & 26 \\
Zone 2 & 1 & 1.23 & 19.2 \\
& 86 & 14.0 & 28.6 \\
\hline
\end{tabular}




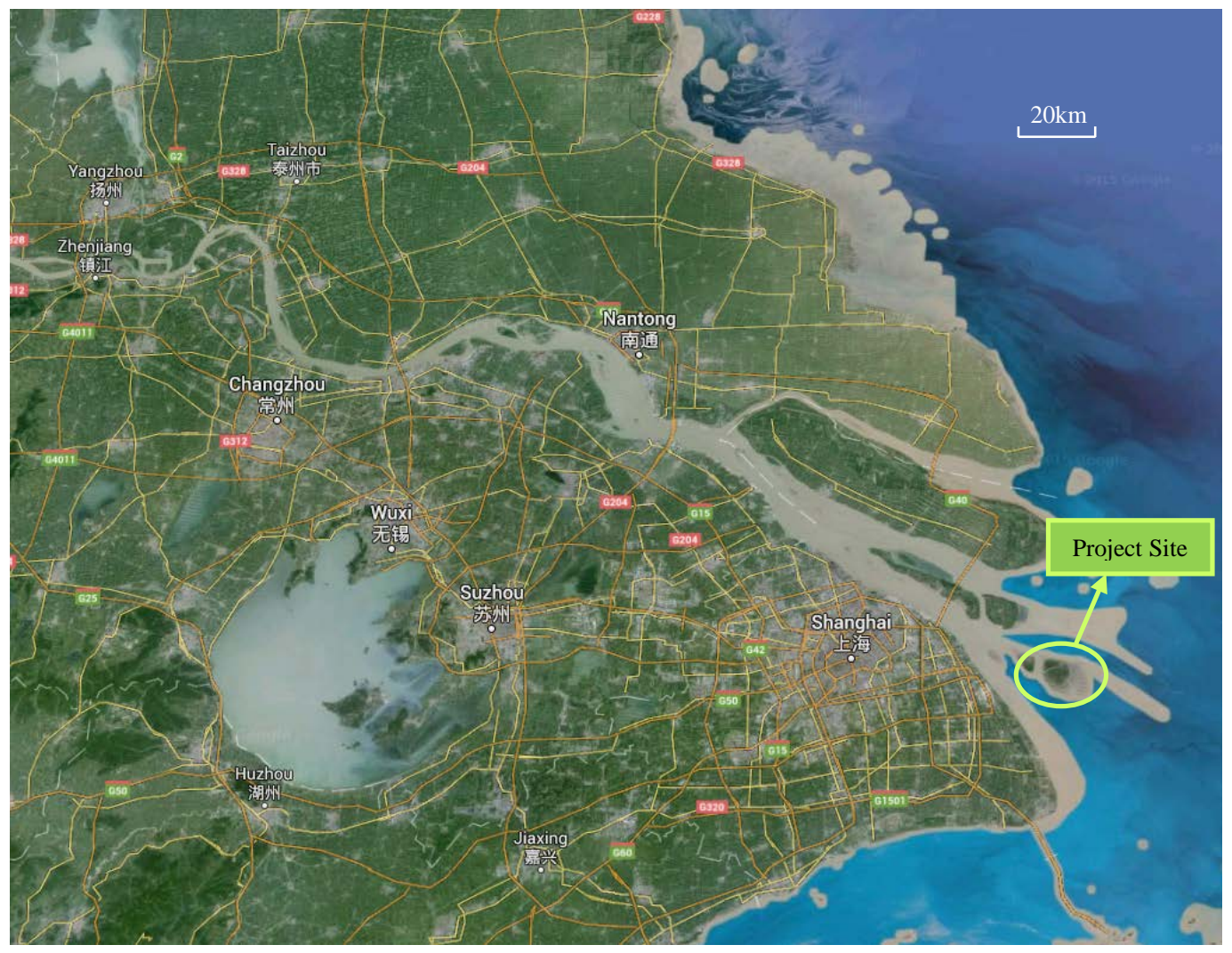

Figure 1. Location of the study site for Hengsha reclamation project 

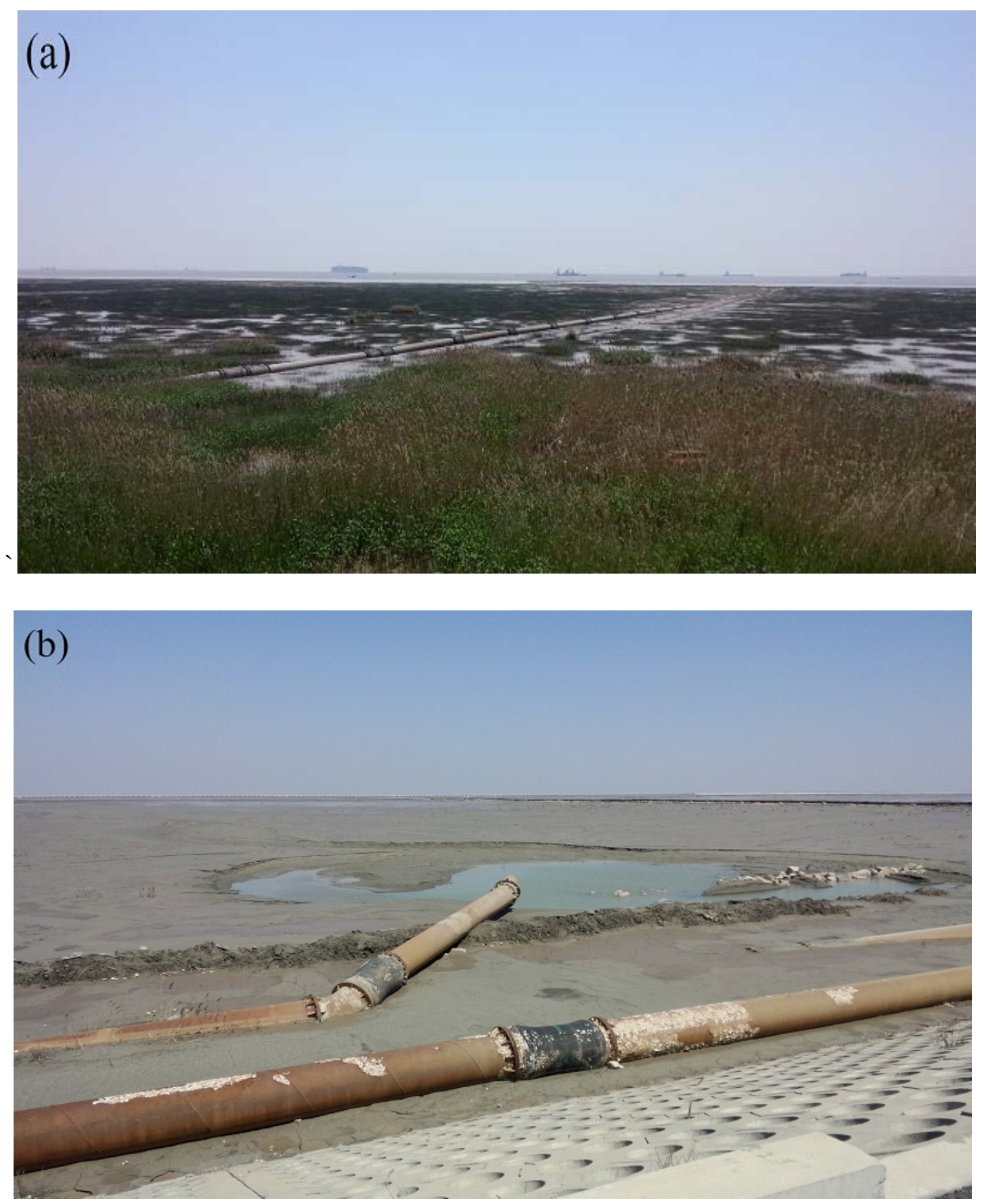

Figure 2 Project site reclaimed filled with non-solidified dredged soils (a) Part of reclaimed land for Hengsha east shoal reclamation project; (b) Project site for current study 


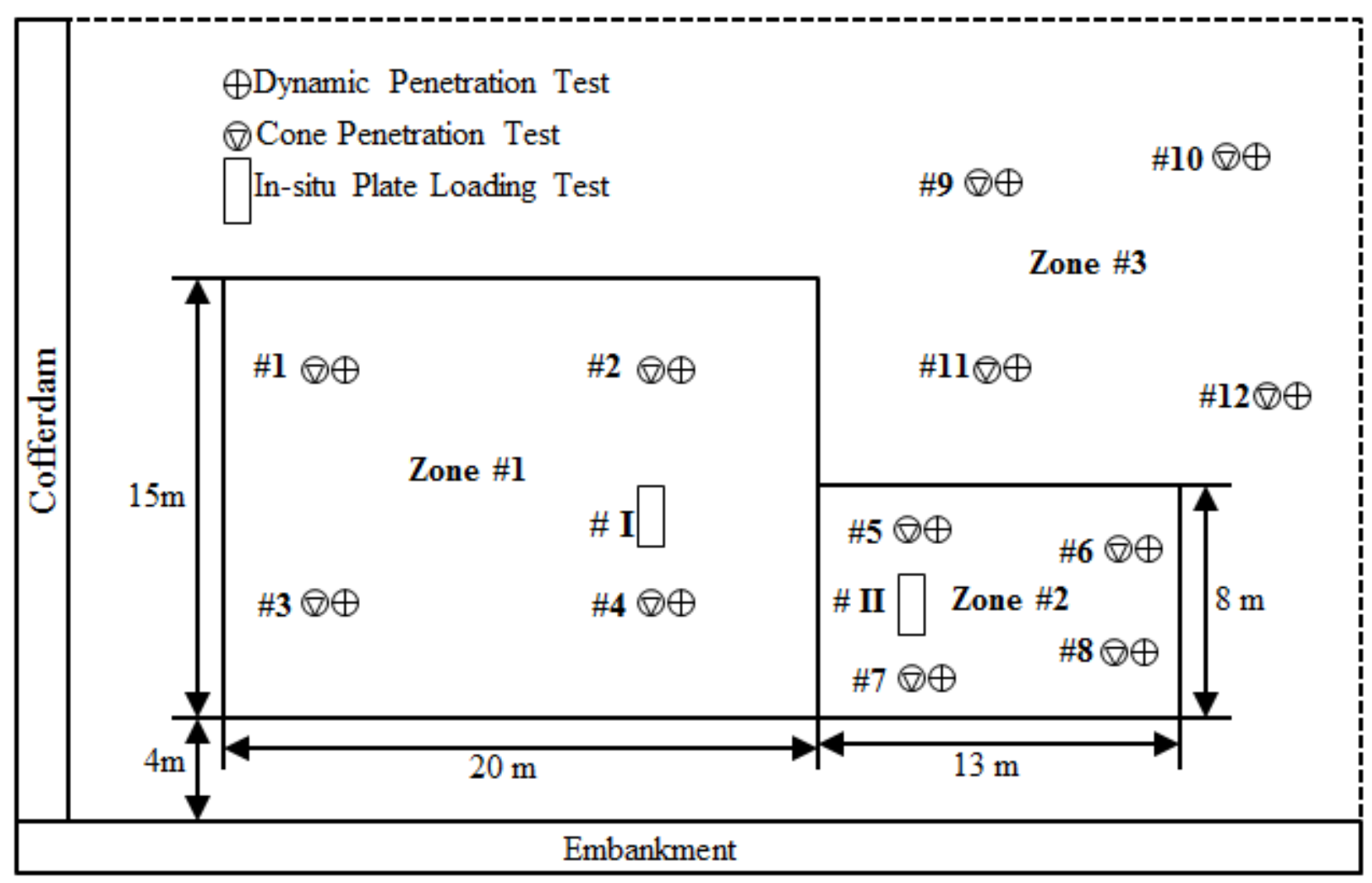

Figure 3 Layout of In-situ field testing points 


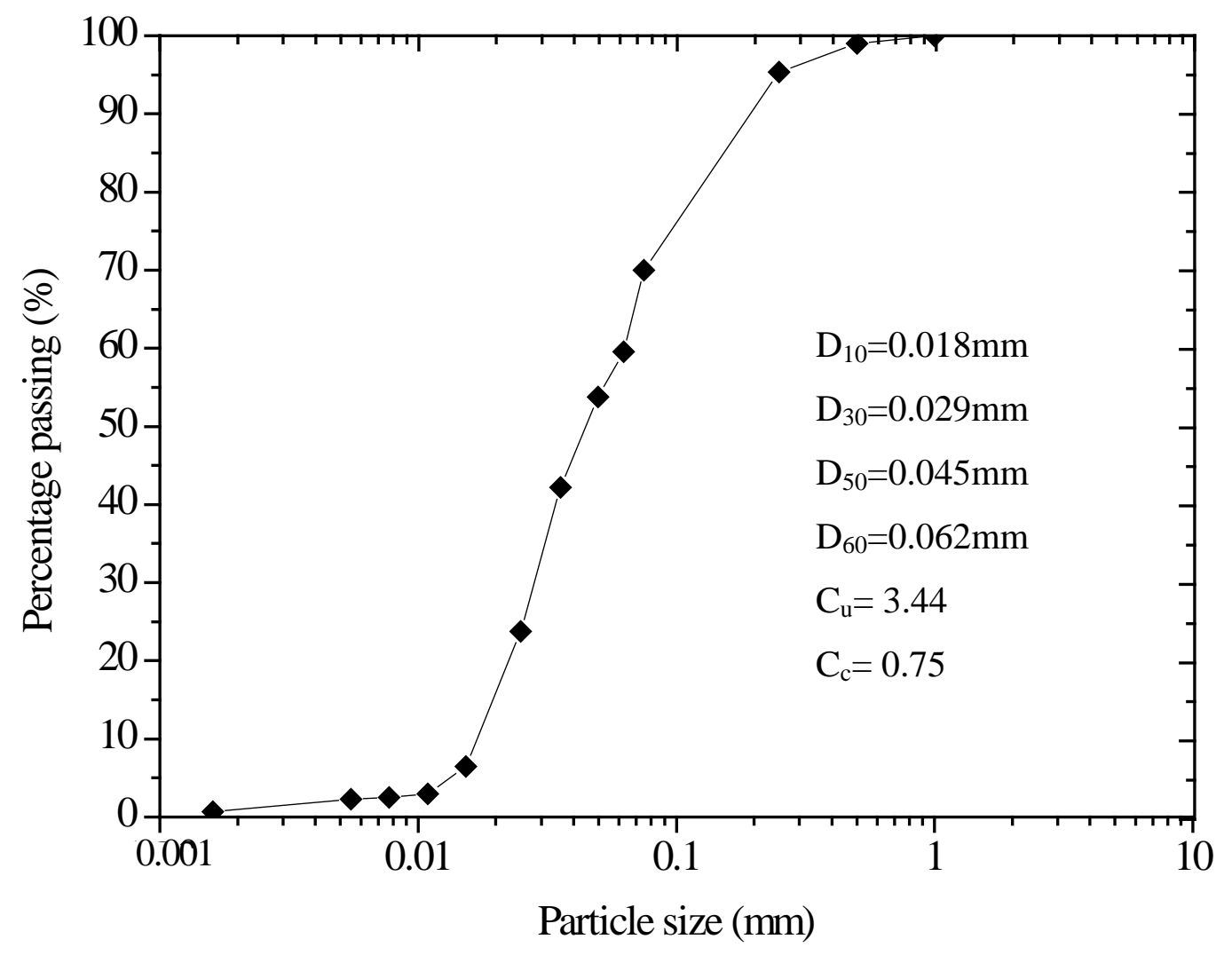

Figure 4 Particle size distribution of typical fresh dredged marine soil 


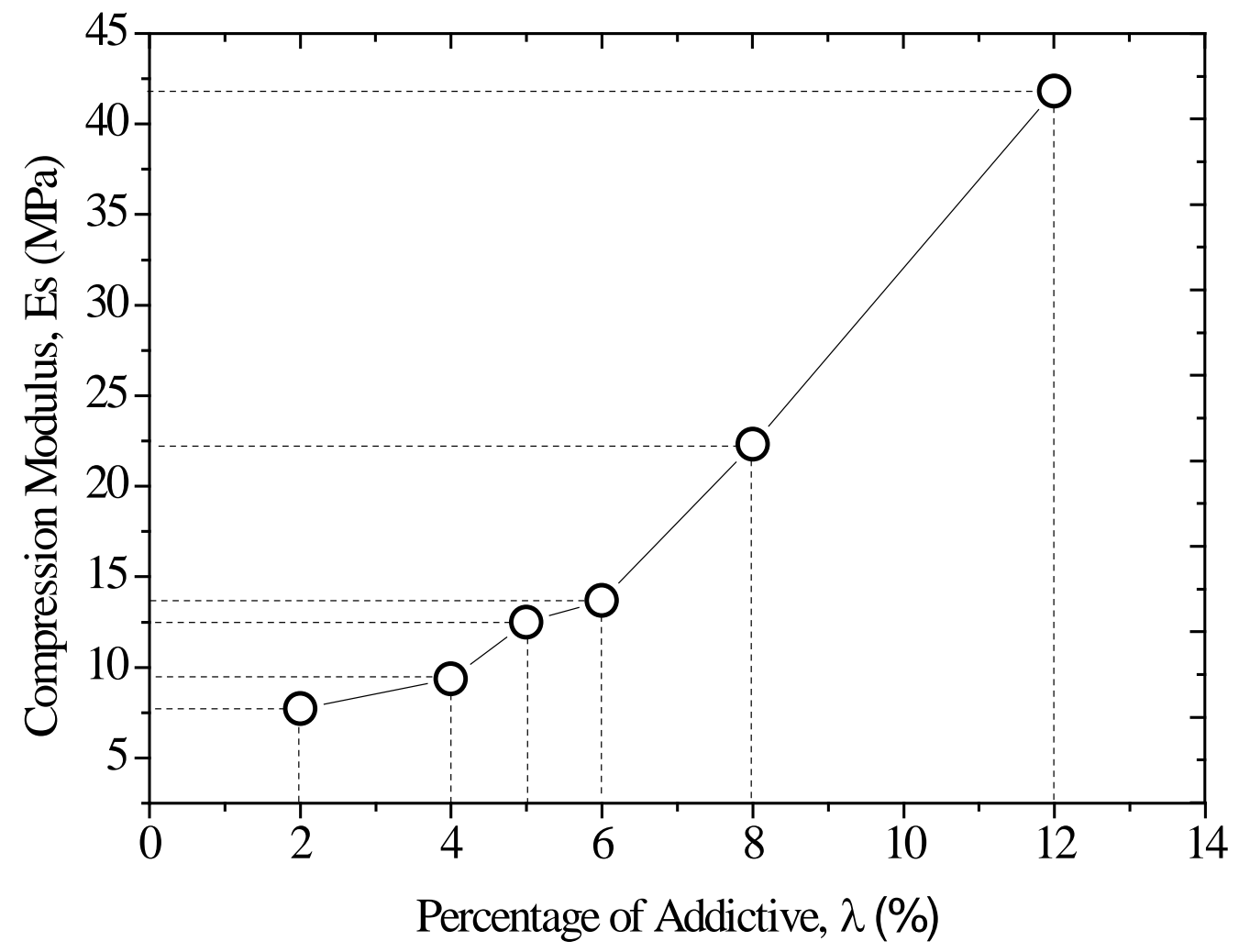

Figure 5 Variation of Compression modulus Es with different mixing ratio $\lambda$ for solidified dredged materials. 
(a) Old system designed by Sakamoto (1998) (OS-1)

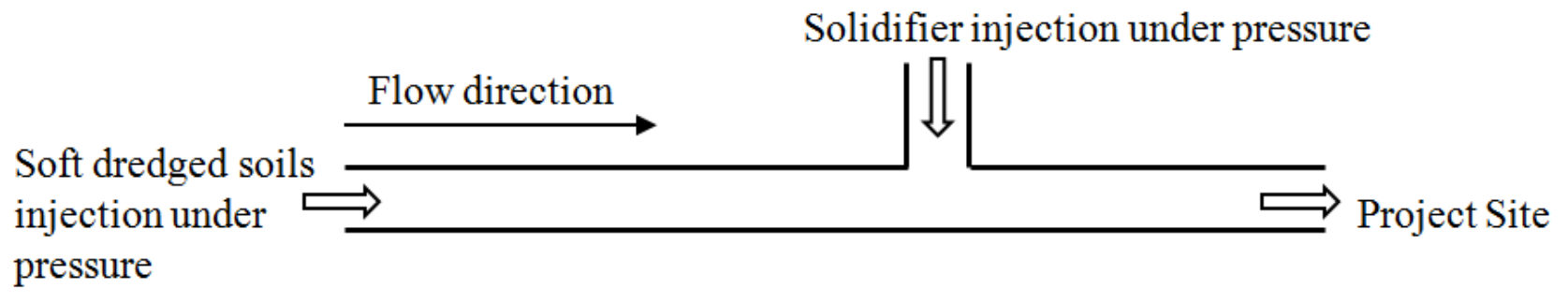

(b) Old system designed by Sakamoto (1998) (OS-2)

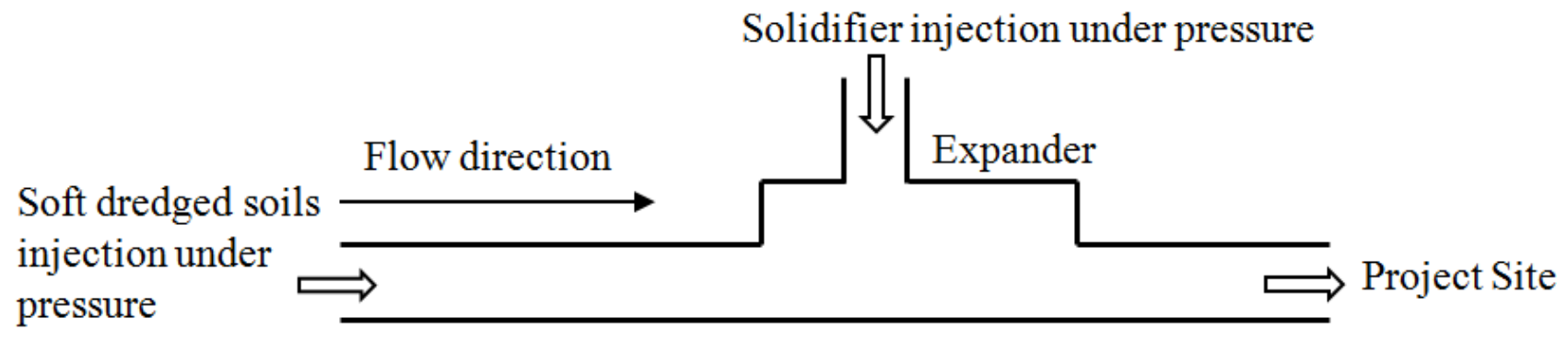

Figure 6 Schematic illustrations of the mixing and transportation systems by Sakamoto (1998) 
(a) Newly designed system used for Zone \#1 (NS-1)

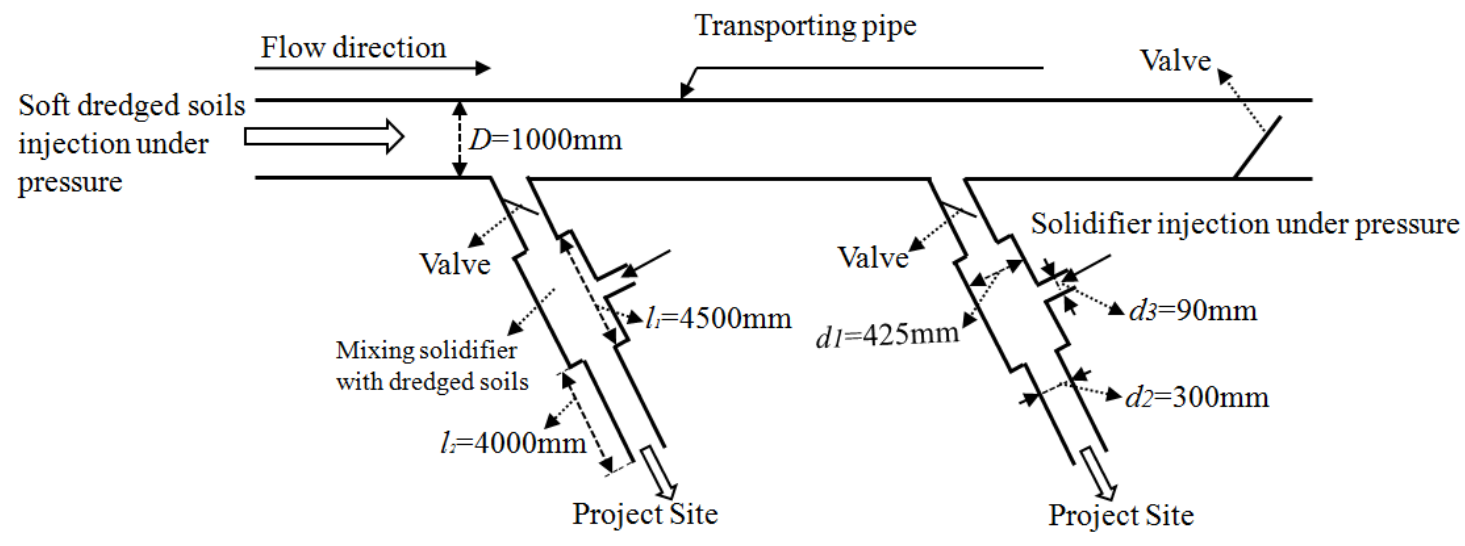

(b) Newly designed system used for Zone \#2 (NS-2)

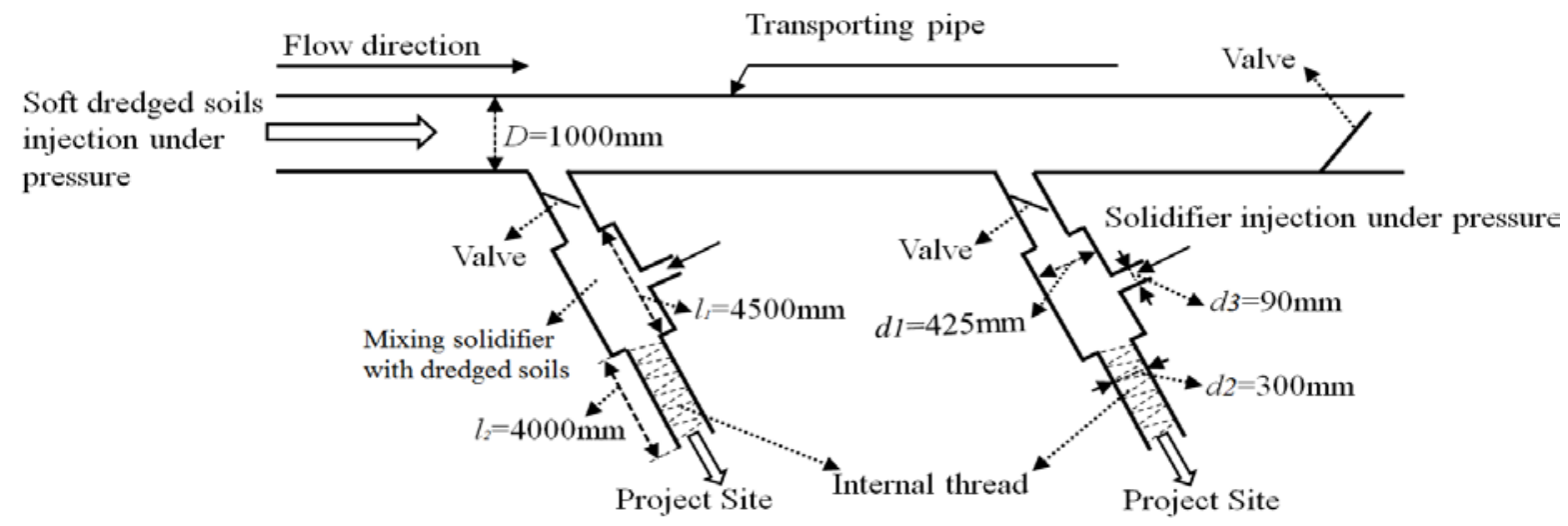

(c) Internal thread

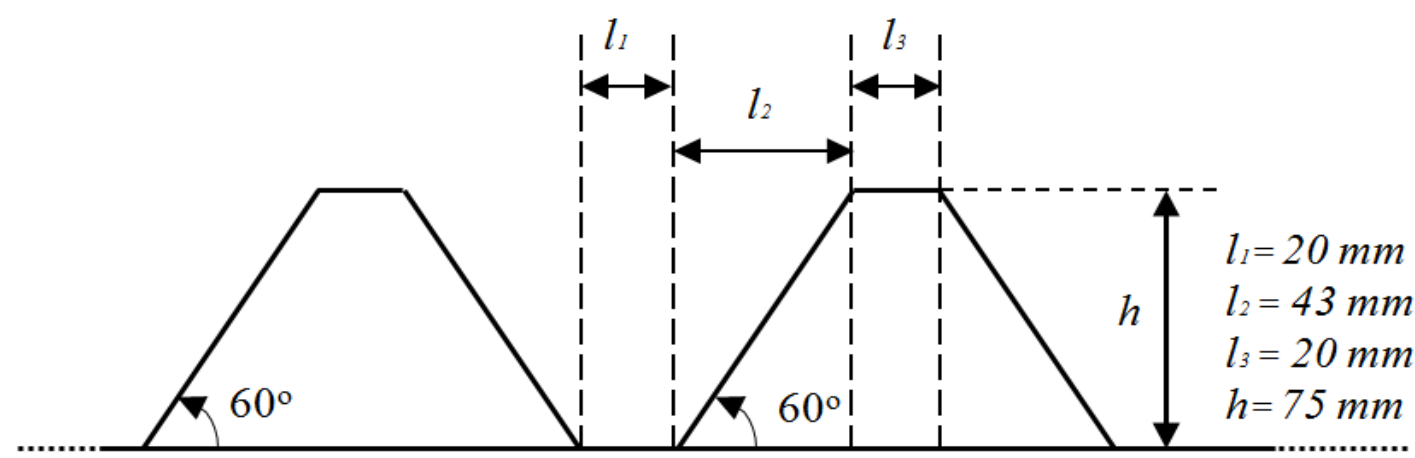

Figure 7 Schematic illustrations of newly designed mixing and transportation systems 

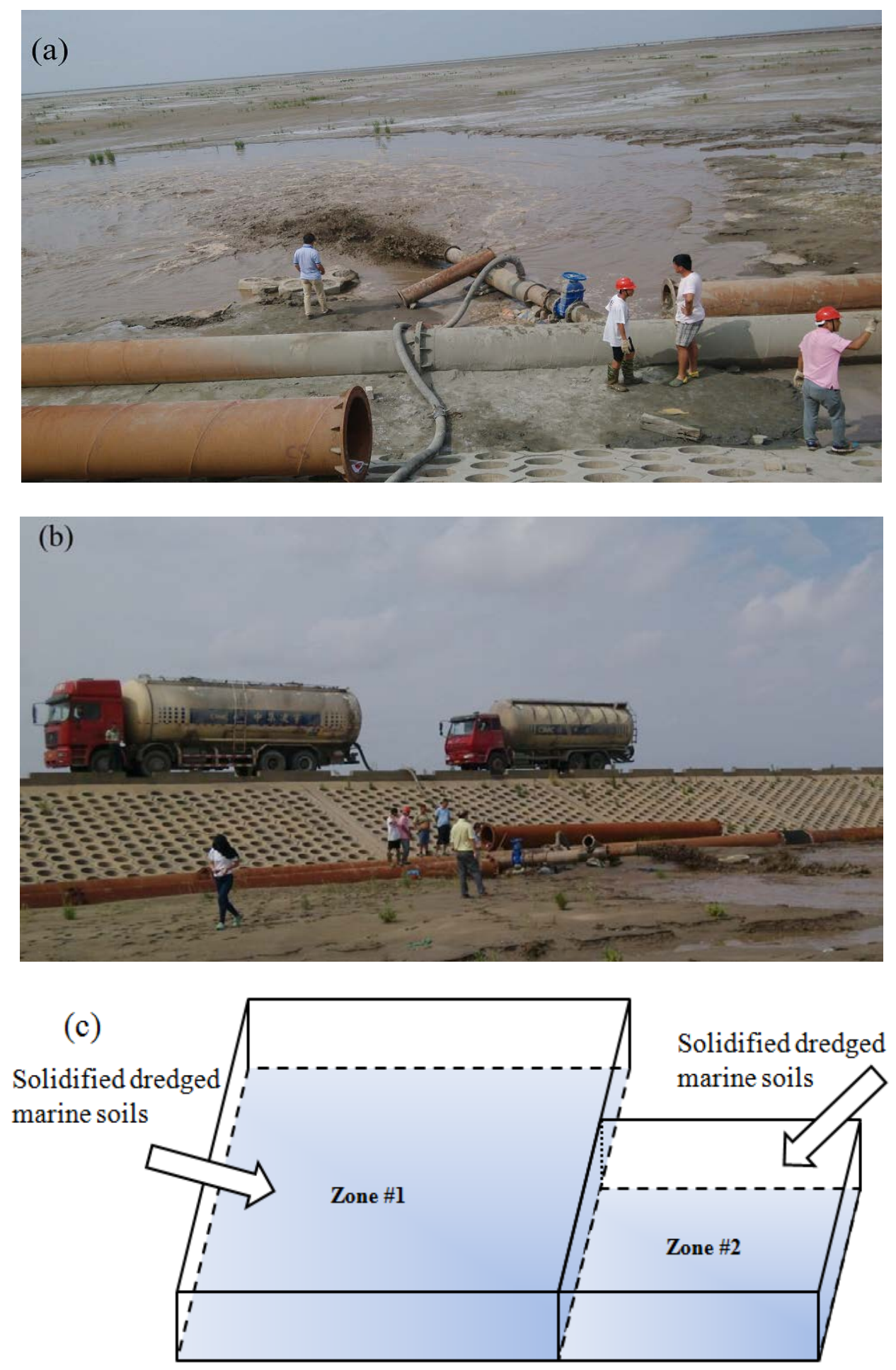

Figure 8 Construction site for land reclamation using solidified dredged fills (a) dumping solidified dredged marine soils into the project site; (b) pumping additive powder into fresh dredged marine soils prior to dumping process (c) Schematic illustration of land reclamation work in this study (Zone 1 and Zone 2) 


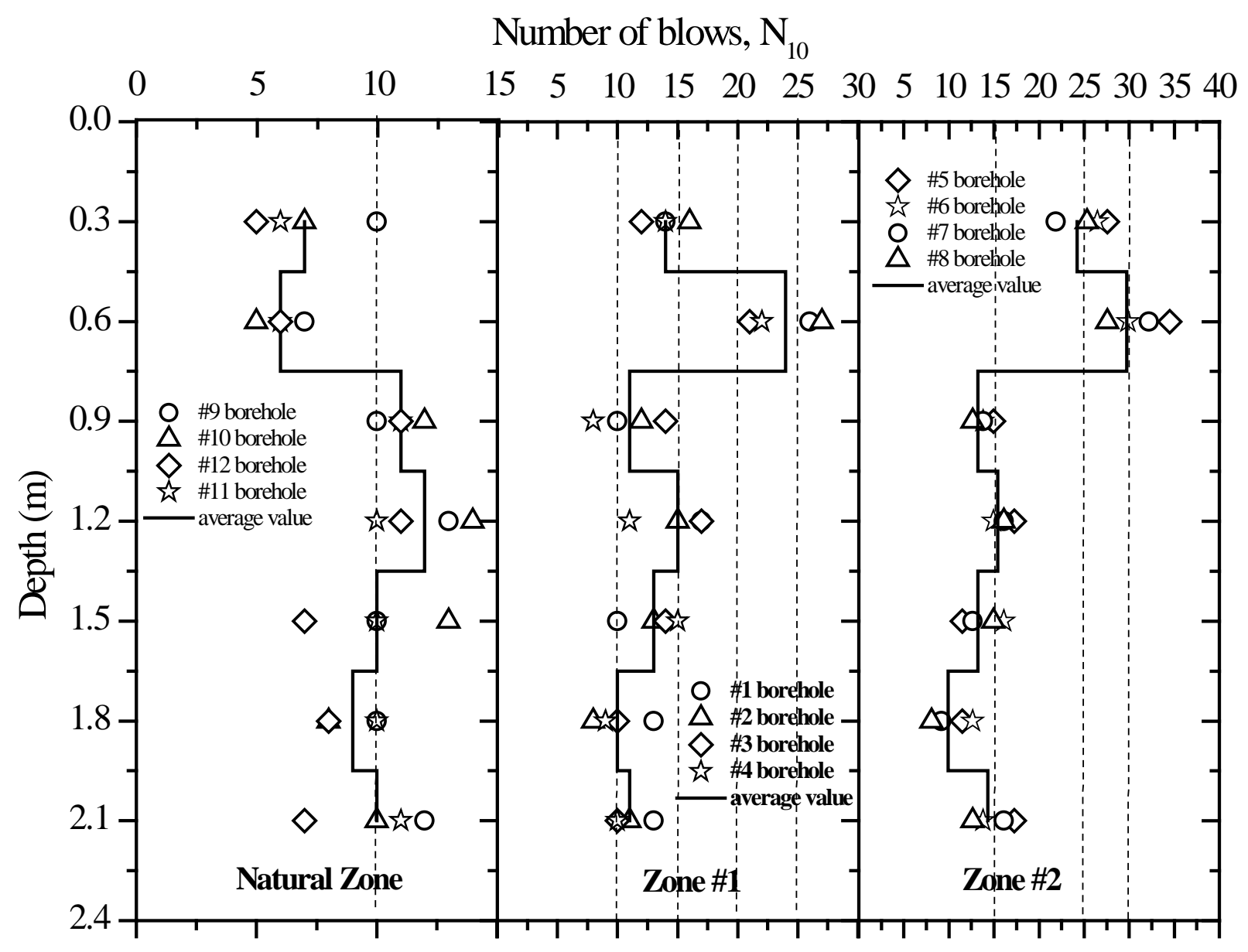

Figure 9 Comparison of In-situ Dynamic Penetration Test results for the natural reclaimed and the treated land 


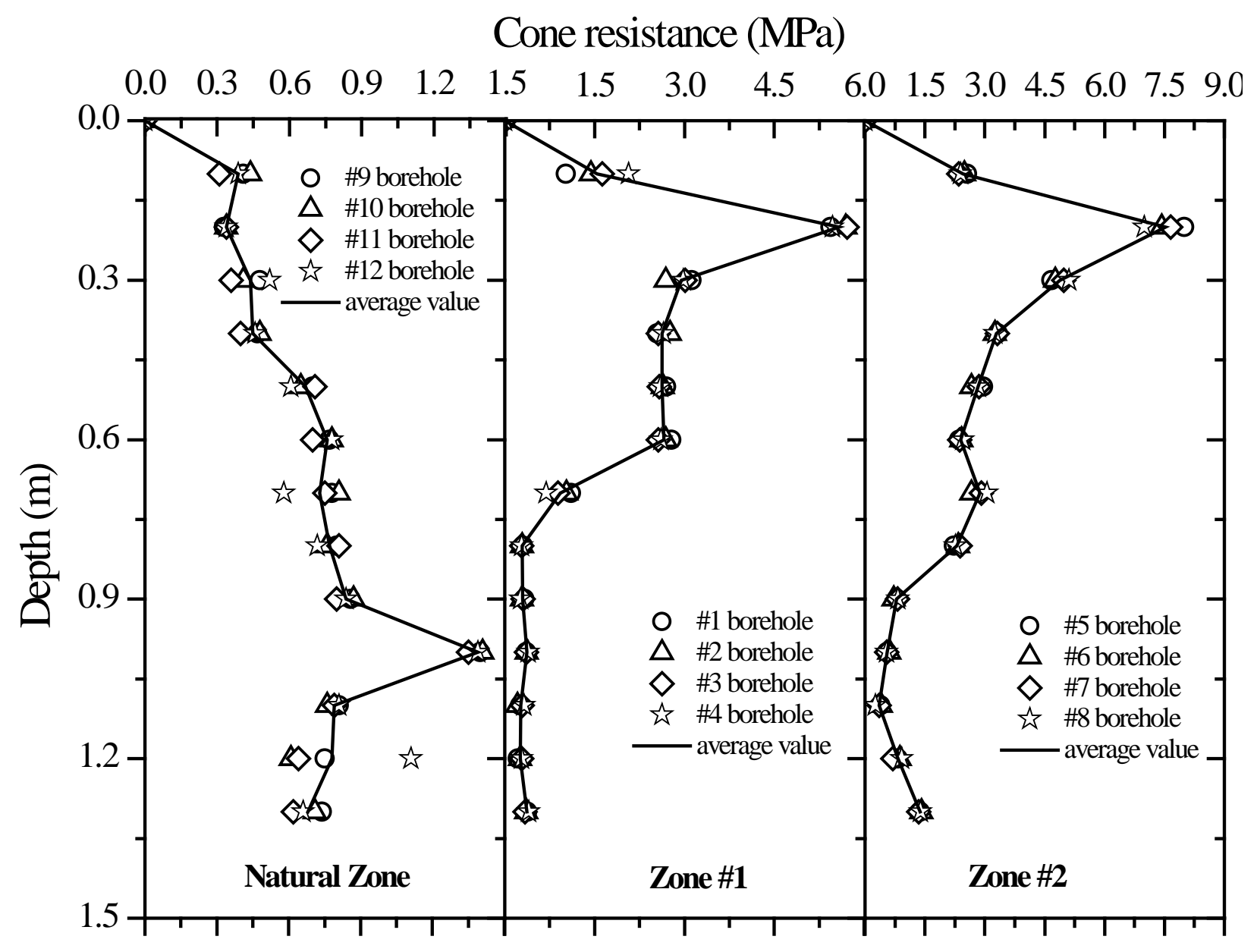

Figure 10 Comparison of cone penetration test results for the natural reclaimed and the treated land 


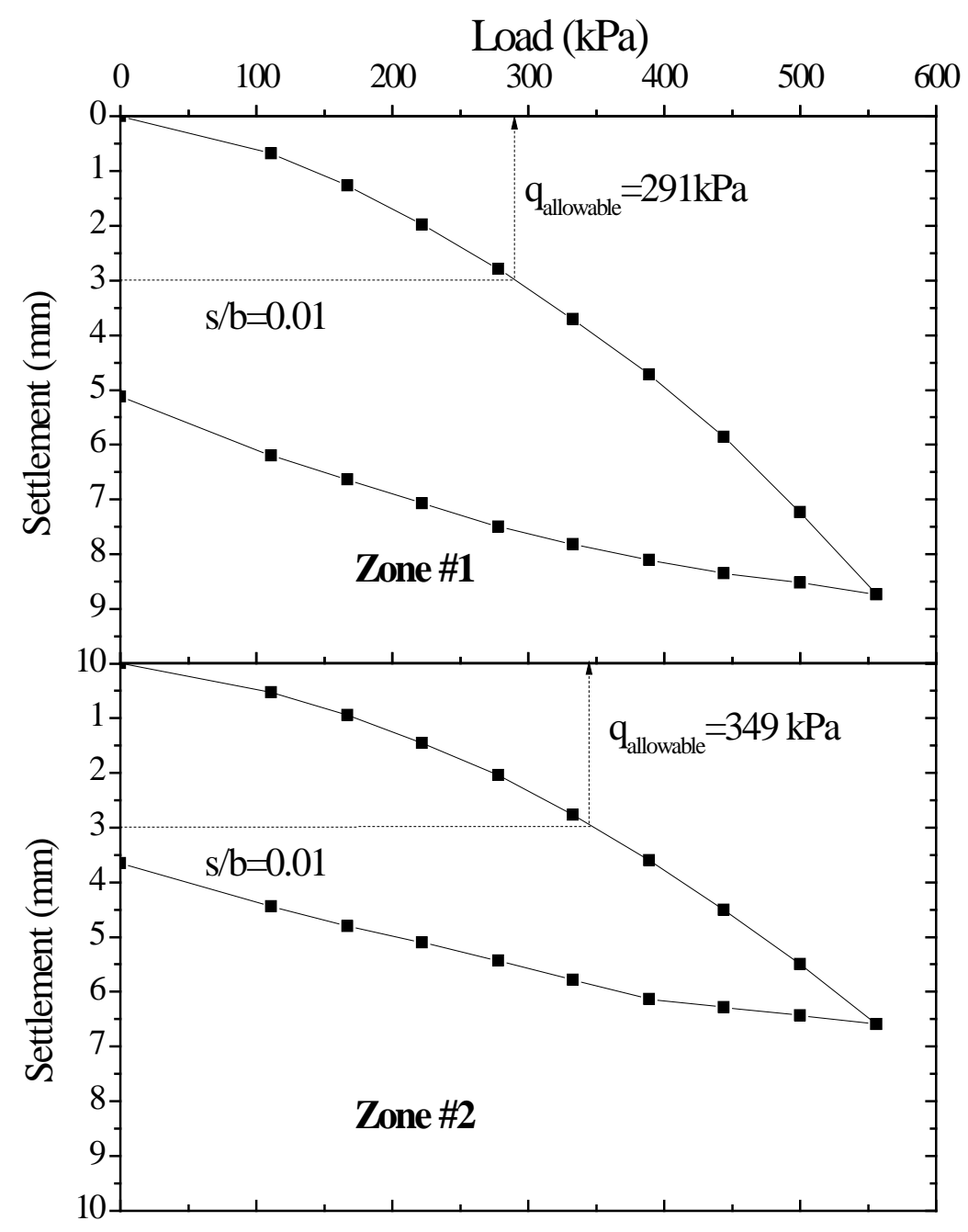

Figure 11 Comparison of In-situ Plate Loading Test results for the natural reclaimed and the treated land 